\title{
Injuries among young workers in career- technical-vocational education and associations with per pupil spending
}

\author{
Derek G. Shendell ${ }^{1 *}$ (D), Saisattha Noomnual ${ }^{2}$, Jesse Plascak ${ }^{3}$ and Alexsandra A. Apostolico 2,4
}

\begin{abstract}
Background: New Jersey Department of Education (NJDOE) requires by law for accidents/incidents (injury) involving career-technical-vocational education (CTE) students and staff to be reported within five business days to the NJ Safe Schools Program (NJSS) using an online surveillance system. NJ public schools and charter schools (CS) through school districts (SD) or county offices report school data annually to NJDOE, including per pupil spending (PPS). In this study, we examined potential associations of PPS with several variables on injury in NJ: injury cause, injury location on the body, injury type, injury severity, use of PPE, and location of treatment for injury.

Methods: PPS data for December 1998-June 2015 from CTE SDs (one per NJ county, $n=21$ ), four CS SD and eight county special services districts were analyzed. T-test examined potential differences in PPS regarding injury severity and use of personal protective equipment (PPE). Stepwise logistic regression assessed potential associations between PPS and various injury surveillance variables.

Results: There were more CTE injuries reported among SD with lower PPS than among SD with higher PPS. Relatively less severe injuries, e.g., bruise/bumps and cuts/lacerations, more often occurred at schools and SD with higher PPS. Conversely, relatively more severe injuries, e.g., fractures, more often occurred at schools and SD with lower PPS.

Conclusion: Future research should further investigate disparities regarding younger worker injuries reported within school-based career-technical-vocational education programs by PPS and other factors like sex or gender, severity, safety training provided and work experience at time of injury.
\end{abstract}

Keywords: Adolescents, High schools, Injury, Per pupil spending, Secondary schools, Young workers

\section{Background}

Unintentional injuries among adolescents and young adults age 21 and younger, an already susceptible, vulnerable subpopulation, are ongoing public health concerns. Approximately 18.1 million young workers under age 24 comprised about $13 \%$ of the workforce in the U.S. in 2013. [1] In 2012, 375 young U.S. workers died from work-related injuries. [1] In 2009, there were approximately 26,500 emergency-department (ED) treated illnesses and injuries among 15-17 year-old youth workers in the U.S., and it was estimated by the U.S. Centers for Disease Control and Prevention-National

\footnotetext{
* Correspondence: shendedg@sph.rutgers.edu

${ }^{1}$ Environmental and Occupational Health And New Jersey Safe Schools Program (NJ SS) Rutgers School of Public Health, 683 Hoes Lane West, 3rd Floor SPH Building, Piscataway, NJ 08854-8020, USA

Full list of author information is available at the end of the article
}

Institute of Occupational Safety and Health (NIOSH) only about one-third of incidents were even treated at hospitals. [2] Furthermore, in 2009, 4380 illnesses and injuries among workers under age 18 in the U.S. required at least one day away from work; this number excluded workers at small farms, local agencies and if self-employed. [2] Compared to older adults, these higher numbers of young worker injuries may relate to their inexperience, lack of safety and health knowledge and awareness due to a lack of proper training, cultural and economic barriers, and their biological and physiological characteristics, e.g., inadequate strength and cognitive skills to operate some potentially hazardous manual and automatically operated equipment for certain tasks. $[1,3,4]$

(c) The Author(s). 2018 Open Access This article is distributed under the terms of the Creative Commons Attribution 4.0 International License (http://creativecommons.org/licenses/by/4.0/), which permits unrestricted use, distribution, and 
Secondary school resources such as per pupil spending (PPS), class size, teachers (e.g., numbers or teacher-tostudent ratio), and the quality and content of curriculum are factors potentially influencing safety and health outcomes among students; several of these factors also relate to socioeconomic status (SES) indicators. Previous studies have suggested childhood injury outcomes, in terms of morbidity and mortality, varied by SES. Among students in supervised, school-sponsored career-technical-vocational education (CTE) programs, SES may influence reported injuries. [5] However, at present, few data exist on potential associations between PPS and injury and illness-overall or work-related-among secondary school students.

PPS has been defined to include money from federal, state, and local sources, and has varied among states, ranging from the lowest PPS state, Utah $(\$ 6555)$ to the highest, New York $(\$ 19,818)$; New Jersey was among higher PPS states $(\$ 17,572)$. [6] Recent research suggested adolescents attending schools with higher PPS had increased scores on the adult health utility index, and college students in the top quartile of PPS had a higher adult utility index score than those in the bottom quartile of PPS. [7] These findings also were supported by sibling fixed models, which suggested individuals who attended schools with higher PPS have better subsequent health outcomes than their siblings who attended schools with lower PPS. [7] Another study reported increased PPS was associated with decreased physical assault among educators. [8] Another study suggested U.S. schools with higher PPS more often prohibited use of physical activity as punishment in physical education. [9] Furthermore, in those higher PPS schools, nurse-to-student ratios and physician-provided services to students at school were higher, and they were also more likely not to offer brand-name fast food to students. [9]

Other studies besides those on PPS have suggested SES was an important factor for getting injured in general, whether non-fatal or fatal injuries, in particular among adolescents and young adults. [10] It must also be noted non-fatal injuries can be severe; youth workers can have permanent disabilities and work restriction. [11] Research also suggests higher parental SES was significantly associated with decreased work-related injuries among adolescents. [12] However, data are limited on associations between SES indicators, including PPS, and work-related injuries among adolescents and young adults, particularly on students enrolled in CTE programs.

CTE programs offer a great opportunity to prepare students-adolescents and young adults-to enter the work force, and encompass youth who could drop out from traditional schools. There are over 20,000 CTE and "Ready to Work" programs in the U.S. financially supported by the federal government (over $\$ 1$ billion). [13] Moreover, students in CTE programs have been more likely to report having been informed of legal rights and having received safety training than those working outside of these structured programs. [14] The U.S. Office of Vocational and Adult Education previously estimated, on average, every high school student has taken at least one CTE course, and 1-in-4 students completed three or more courses in a single program area. [13]

Based on NJ Administrative code 6A:19-6.5, the New Jersey Department of Education (NJDOE) requires by law for accidents/incidents (injury or illness) involving CTE students and/or staff treated by a licensed physician, physician's assistant, or advanced practice nurse to be reported to the NJ Commissioner of Education. [15-17] Incidents are directly reported to the NJ Safe Schools Program (NJSS) online surveillance system (via Psychdata) for aggregate analyses.

Data on incidence of injuries reported from CTE schools in NJ between 12/1998-12/2013 were described in a prior paper examining associations with District Factor Groups (DFG) scores as one potential indicator of area-level SES. [5] In the present study, we examined potential associations between injuries reported from students enrolled in NJ CTE schools and school district (SD)-level PPS. Although PPS is a SES indicator commonly used throughout the U.S., no known study has simultaneously tested whether DFG scores or SD-level PPS both are associated with injury characteristics occurring within CTE schools. Moreover, PPS is a more specific measure of SES than DFG scores. The DFG scores are derived from U.S. Census-based sociodemographic variables, but PPS is a direct reflection of monetary resources spent within each SD.

Specifically, in this paper, we examined potential associations of PPS with several key variables: injury cause, injury location on the body, injury type, injury severity, use of PPE, and location of treatment for injury. We hypothesized lower PPS school districts would have relatively more severe injuries, use PPE less often, and have higher number of reported injuries treated at hospitals/ED compared to SDs with higher PPS. In the present analyses, data collected through the NJSS incident reporting surveillance system between the years $12 / 1998-06 / 2015$, i.e., 1.5 years more data than prior analyses, [5] were used along with PPS data from CTE and charter schools (CS) in NJ for state fiscal years 1998-2015. [18]

\section{Methods}

Aggregate, de-identified injury surveillance data were used; there was no personal, identifying information. The Rutgers University-New Brunswick Institutional Review Board (IRB) has approved NJ Safe Schools Program incident surveillance and training-related evaluation activities as exempt research since they are based on various laws (IRB \#021997 W0383). Overall, most injury reports were 
students (96\%), with the remaining $4 \%$ of injuries being acquired by school staff (adults); these reports were excluded in further analyses.

PPS data were abstracted from a NJDOE database [18] and were expressed with different terms throughout the State of NJ Fiscal Year (FY) records as Total Cost Per Pupil (1999-2002), Total Comparative Cost Per Pupil (20032010), Budgetary Per Pupil Cost (2011-present), and Total Spending Per Pupil (2011-present). The definition of each term was similar, and served an indicator to allow comparisons of SD costs. The SD cost included a SD's general fund and special fund budgets related to services for enrolled students. Other costs included in these indicators were costs of governance, support, and instruction considered common and generally uniform, i.e., staff salaries and fringe benefits, textbooks, supplies and materials, rentals and insurance, legal fees and other purchased professional, technical and property services. The former three indicators are different from the Total Spending Per Pupil. The Total Spending Per Pupil also includes state expenditures (i.e., pensions and social security payments) on behalf of the SDs; transportation costs (including costs for students transported to non-public/private and CS); and, legal judgments against the SD. In addition, Total Spending Per Pupil includes food services expenditures, including those covered by school lunch fees; capital spending budgeted in the general fund (facilities and equipment); special revenues supported by local, state, and federal revenues; payments by one SD to other private and public SD for the provision of regular, special, and preschool education services; school departments; and, an estimate of the SD's share of the debt service the State of $\mathrm{NJ}$ is paying for school construction bonds issued for school construction grants and School Development Authority Projects. In this study, we did not use the Total Spending Per Pupil because data were only available 2011-2015. Instead, in this study, the indicator used was PPS, i.e., reflecting Total Cost Per Pupil, Total Comparative Per Pupil Cost, or Budgetary Per Pupil Cost (similar definitions). PPS of each SD for the 1998-2015 school/academic years (state fiscal years) were managed in Microsoft Excel by school types-- secondary schools of grades $7-12$ or $9-12$, county special services SD (CSSD), CTE SD, or charter school (CS) SD. Inflation adjustments to PPS were calculated using monthly consumer price index data specific to the education industry, averaged according to the academic fiscal year (July 1 - June 30), and standardized to 2010 U.S. dollars. [19] To investigate the association between annual PPS and work-related high school injuries, reported injuries were matched to each school's PPS (based on its $\mathrm{SD}$ ) by academic year.

As detailed elsewhere, [5] the year 2000 DFG scores were averaged at the county level and linked to each county/SD's CTE program. This was necessary because despite each CTE program being reported separately as approved within a city/town SD or the county-wide service area, it could not receive a separate DFG scores because any student within the county (as opposed to geographically based local SD within a county) could attend the respective county-based CTE SD or special services SD.

\section{Data analysis}

The distributions of mean PPS of CTE SDs and CTE plus non CTE SDs (i.e., eight CSSD and four CS SDs) were slightly right-skewed. In this study, PPS was categorized into higher PPS and lower PPS based on above and below the 50th percentile, respectively.

Statistical analyses were conducted within SPSS 24 (IBM) and SAS 9.4 (Cary, North Carolina). Data were not normally distributed and were $\log$ transformed. T-test assessed potential differences in PPS among reported injury severity groups (i.e., non-disabling, temporary disabling, permanent disabling, and death) and PPE used at time of incident. Multilevel logistic regression assessed potential associations between PPS and reported injury severity, adjusting for potential confounding factors and correlation of individuals within SDs. [20]

\section{Results}

There are twenty-one county CTE SDs in NJ. The twenty-one counties in NJ had at least one SD submit an injury report between 1998 and 2015. There was a wide range of PPS among CTE SDs, from approximately $\$ 6700$ to $\$ 40,600$ during the $1998-2015$ school years. When eight CSSD and four CS SDs were included in the analysis, the range of mean PPS increased (\$8000 - \$66,200). The differences between highest and lowest SD PPS values annually were approximately 60-90\%. (Tables 1-3) Average annual PPS trends indicate that inflation-adjusted PPS has generally declined from academic year 1998-1999 to most recent data (Tables 2 and 3). Comparing longitudinal trends between the CTE SDs (Table 2) and CTE together with eight CSSD and four CS SDs (Table 3) suggests that CTE SDs have experienced a greater PPS decline than CSSD and CS SDs. On average, Hudson County CTE SD had the highest PPS (about \$24,000) while Hunterdon County CTE SD had the lowest PPS (about \$8000). The PPS of Bergen, Camden and Cape May County CTE SDs tended to increase annually, whereas in other CTE SDs, PPS fluctuated over time.

In this analysis, we focused only on PPS of CTE SDs depending on the injury report data. There was higher incidence of injuries among males (72\%) than females (28\%) (Table 4). The most commonly injured body parts were hands and fingers, and the most commonly reported injury type was cuts/lacerations. [16, 17] Also, $55 \%$ of injuries were treated at a hospital/ED compared to $45 \%$ being treated at an outpatient clinic. Overall, injury severity was primarily non-disabling (70\%), followed 
Table 1 Average per pupil spending (PPS) of State of New Jersey (NJ), career-technical-vocational education (CTE), county special services district (CSSD), and charter school (CS) school districts (SDs) in Fiscal Years 1998-99 to 2014-15

\begin{tabular}{|c|c|c|c|c|c|c|c|}
\hline \multirow[t]{2}{*}{ Type of school districts } & \multirow[t]{2}{*}{ Total (n) } & \multirow[t]{2}{*}{ Mean \pm S.D. mean } & \multirow[t]{2}{*}{ Min } & \multirow[t]{2}{*}{ Max } & \multicolumn{3}{|c|}{ Percentile } \\
\hline & & & & & 25 & 50 & 75 \\
\hline$\overline{\mathrm{CTE}^{a}}$ & 21 & $18,413 \pm 5951$ & 6752 & 40,612 & 14,766 & 17,447 & 22,061 \\
\hline CTE, CSSD and CS $^{b}$ & 33 & $23,954 \pm 12,917$ & 6752 & 66,199 & 14,800 & 19,014 & 30,591 \\
\hline
\end{tabular}

${ }^{1}$ Values reported in inflation adjusted, 2010 U.S. dollars

aPPS of only 21 CTE school districts from Fiscal Year (FY) 1998-99 to 2014-15 were used for analysis

bPPS of 21 VOC and eight CSSD school districts from Fiscal Year 1998-99 to 2014-15, and four CS SDs, were used in analysis

For CS SDs, the available data of each school district were as follows: Academy Charter School, Monmouth County from FY 1998-99 to 2014-15; Charter

Technology, Atlantic County from FY 1999-2000 to 2014-15; Camden Academy, Camden County from FY 2001-02 to 2014-15; and, University Academy, Hudson

County from FY 2002-03 to 2014-15

by temporarily disabling (30\%); only one incident was considered a permanent disability as a finger amputation. The PPE usage was about evenly distributed among use (51\%) and no use (49\%).

When stratified by PPS-higher and lower, defined as above and below median at $\$ 14,694$, respectively-results suggested about two-thirds (68\%) of injury incidents were among lower PPS SDs and about one-third (32\%) of injury incidents were among higher PPS SDs. Moreover, the percentage injuries considered to be more severe (temporarily disabling) varied by PPS; $26 \%$ of all injuries within higher PPS SDs were temporarily disabling compared to $34 \%$ of such injuries in lower PPS SDs (Table 5). After adjustment for county DFG score, location of treatment, and year of injury, there was a
' $n$ '-shaped relationship between inflation-adjusted PPS and injury severity. The probability of experiencing a more severe injury (Fig. 1) increased with increasing PPS only up to a PPS of $\$ 20,000$. Among PPS SDs with greater than $\$ 20,000$ the probability of experiencing a more severe injury decreased with increasing PPS.

Statistically significant differences were observed between PPS and nature of injury (results not tabulated). There were significantly higher number of reported injuries, i.e., bruises/ bumps $(p<0.001)$, cut/laceration $(p=0.03)$, and other, e.g., pain, seizure, bloody nose, and fainted $(p=0.04)$, among higher PPS than lower PPS SDs. There was significant higher reported incidence of fractures, which are a relatively more severe type of injury, among lower PPS than higher PPS SDs $(p=0.001)$. Also, statistically significant differences

Table 2 Annual per pupil spending of career-technical-vocational education school districts in the State of New Jersey $(n=21$ counties, one per county) $)^{a}$

\begin{tabular}{|c|c|c|c|c|c|c|c|}
\hline \multirow[t]{2}{*}{ School Year } & \multirow[t]{2}{*}{ Total (n) } & \multirow[t]{2}{*}{ Mean \pm S.E. mean } & \multirow[t]{2}{*}{ Min } & \multirow[t]{2}{*}{ Max } & \multicolumn{3}{|c|}{ Percentile } \\
\hline & & & & & 25 & 50 & 75 \\
\hline 1998-1999 & 21 & $22,084 \pm 6627$ & 12,384 & 40,613 & 17,714 & 21,615 & 26,486 \\
\hline 1999-2000 & 21 & $22,455 \pm 6416$ & 7113 & 37,883 & 18,452 & 22,151 & 24,910 \\
\hline 2000-2001 & 21 & $22,986 \pm 6050$ & 11,137 & 37,048 & 19,258 & 25,469 & 26,922 \\
\hline 2001-2002 & 21 & $20,976 \pm 5846$ & 9697 & 34,560 & 16,266 & 21,865 & 24,311 \\
\hline 2002-2003 & 21 & $19,837 \pm 5475$ & 9923 & 34,542 & 16,680 & 19,992 & 22,390 \\
\hline 2003-2004 & 21 & $18,966 \pm 5927$ & 8332 & 33,649 & 15,959 & 19,057 & 21,888 \\
\hline 2004-2005 & 21 & $18,989 \pm 5391$ & 9558 & 33,270 & 16,170 & 18,482 & 22,628 \\
\hline 2005-2006 & 21 & $19,026 \pm 5780$ & 9160 & 31,307 & 15,464 & 18,150 & 22,490 \\
\hline 2006-2007 & 21 & $18,542 \pm 5454$ & 8451 & 33,074 & 16,294 & 17,627 & 18,876 \\
\hline 2007-2008 & 21 & $17,203 \pm 4642$ & 7125 & 28,996 & 14,912 & 16,243 & 20,416 \\
\hline 2008-2009 & 21 & $16,983 \pm 5210$ & 7466 & 32,652 & 13,745 & 17,233 & 19,155 \\
\hline 2009-2010 & 21 & $16,765 \pm 6111$ & 6752 & 30,584 & 13,014 & 16,705 & 19,014 \\
\hline 2010-2011 & 21 & $15,454 \pm 4907$ & 6862 & 26,285 & 12,436 & 15,250 & 17,444 \\
\hline 2011-2012 & 21 & $15,472 \pm 4734$ & 7469 & 25,858 & 12,683 & 15,341 & 17,005 \\
\hline 2012-2013 & 21 & $14,422 \pm 3761$ & 7470 & 22,535 & 11,978 & 14,588 & 16,003 \\
\hline 2013-2014 & 21 & $14,450 \pm 3473$ & 8256 & 22,306 & 12,791 & 13,989 & 15,859 \\
\hline 2014-2015 & 21 & $16,939 \pm 999$ & 10,292 & 28,230 & 13,600 & 16,266 & 18,985 \\
\hline
\end{tabular}

${ }^{a}$ Values reported in inflation adjusted, 2010 U.S. dollars

Per pupil spending of each school district was compared in the same state fiscal year (school year) 
Table 3 Annual (school year) per pupil spending (PPS) of career-technical-vocational education (CTE) school districts (SDs), county special services school districts, and charter school (CS) SDs in the State of New Jersey ${ }^{a}$

\begin{tabular}{|c|c|c|c|c|c|c|c|}
\hline \multirow[t]{2}{*}{ School Year } & \multirow[t]{2}{*}{ Total (n) } & \multirow[t]{2}{*}{ Mean \pm S.E. mean } & \multirow[t]{2}{*}{ Min } & \multirow[t]{2}{*}{ Max } & \multicolumn{3}{|c|}{ Percentile } \\
\hline & & & & & 25 & 50 & 75 \\
\hline 1998-1999 & $30($ missing $=3)$ & $27,328 \pm 11,968$ & 12,384 & 61,043 & 18,362 & 23,593 & 34,266 \\
\hline 1999-2000 & $31($ missing $=2)$ & $28,559 \pm 13,350$ & 7113 & 65,508 & 18,452 & 24,698 & 39,483 \\
\hline 2000-2001 & 31 (missing = 2) & $26,369 \pm 9482$ & 11,137 & 51,272 & 19,258 & 25,947 & 30,592 \\
\hline 2001-2002 & $32($ missing $=1)$ & $25,144 \pm 10,690$ & 9697 & 53,346 & 16,111 & 23,319 & 32,122 \\
\hline 2002-2003 & 33 & $23,882 \pm 11,079$ & 9923 & 55,051 & 16,183 & 20,216 & 31,756 \\
\hline 2003-2004 & 33 & $23,455 \pm 11,426$ & 8332 & 53,396 & 15,959 & 19,627 & 32,634 \\
\hline 2004-2005 & 32 & $25,127 \pm 13,379$ & 9558 & 60,345 & 16,405 & 19,791 & 33,983 \\
\hline 2005-2006 & 33 & $24,888 \pm 13,950$ & 9160 & 62,884 & 15,464 & 19,867 & 31,307 \\
\hline 2006-2007 & 33 & $24,565 \pm 13,871$ & 8451 & 61,053 & 16,218 & 17,686 & 33,074 \\
\hline 2007-2008 & 33 & $23,522 \pm 13,923$ & 7125 & 61,843 & 14,128 & 17,146 & 28,996 \\
\hline 2008-2009 & 33 & $22,848 \pm 12,873$ & 7466 & 51,641 & 14,489 & 17,963 & 26,922 \\
\hline 2009-2010 & 33 & $22,974 \pm 14,080$ & 6752 & 62,701 & 13,532 & 17,273 & 30,307 \\
\hline 2010-2011 & 33 & $22,431 \pm 14,958$ & 6862 & 66,199 & 12,799 & 16,367 & 24,996 \\
\hline 2011-2012 & 33 & $21,875 \pm 13,787$ & 7469 & 65,254 & 13,483 & 16,150 & 25,858 \\
\hline 2012-2013 & 33 & $20,991 \pm 13,878$ & 7470 & 65,800 & 13,184 & 15,064 & 22,535 \\
\hline 2013-2014 & 33 & $20,105 \pm 12,501$ & 8256 & 62,614 & 12,791 & 14,842 & 22,306 \\
\hline 2014-2015 & 33 & $25,060 \pm 2863$ & 10,292 & 76,653 & 14,849 & 17,366 & 32,252 \\
\hline
\end{tabular}

avalues reported in inflation adjusted, 2010 U.S. dollars

PPS among SD compared in the same FY; number of SD varied because missing data from CS SD

The available data of CS SD were: Academy Charter School, Monmouth County from FY 1998-99 to 2014-15; Charter Technology, Atlantic County from FY 1999-2000

to 2014-15; Camden Academy, Camden County from FY 2001-02 to 2014-15; and University Academy, Hudson County from FY 2002-03 to 2014-15

were observed between PPS and cause of injury. The injuries among lower PPS SDs were more likely to be caused by fall from elevation $(p=0.03)$; whereas among higher PPS SDs, the injuries were more likely to be caused by caught in/ under/between $(p=0.01)$. The injured body part most often reported was 'other' (e.g., back, thumb, finger, shoulder and fainting), which was higher among lower PPS than higher PPS SDs $(p=0.04)$. The results also suggested no statistically significant difference between PPE usage and injury among higher and lower PPS SDs.

\section{Discussion}

This study suggested a statistically significant difference between SD-level, per pupil spending and various injury characteristics among NJ youth attending CTE programs. The relatively less severe, non-disabling to temporarily disabling injuries like bruises/bumps were more likely to occur at schools/SDs with higher PPS, conversely more severe injuries like fractures were more likely to occur at schools/SDs with lower PPS.

This study also suggested how for reported injuries there was no statistically significant difference in the location of reported injury treatment, i.e., treated at hospitals/EDs versus treated at outpatient clinics. Components of PPS related to health care facilities and doctor/nurse-student ratio may not be substantially different among schools/SDs with varying total PPS. In addition, in this study, health insurance status may not have been an issue for choosing the location of injury treatment. Reported injuries were usually acquired within school-sponsored CTE programs; thus, costs incurred would potentially be covered by the reporting school/SD and/or the student's family. Irrespective of who is responsible for paying for treatment, each trip to an ED costs society around \$200. [21] Therefore, school-based injury prevention remains warranted.

Furthermore, in a previous report by the U.S. Department of Labor, workplace injuries among the adult population placed burdens on the workers, especially low-wage and immigrant workers, and their families, and have contributed to income inequality, another SES indicator. [22] Moreover, previous studies suggested poor families and minorities with higher health disparities and lower child achievement measures were more likely to attend schools with lower PPS than schools with higher PPS. [23] Further school-based research on SES and race/ethnic disparities in reported CTE injuries and potential impacts on academic performance is needed.

\section{Limitations}

There were several limitations of this study. One limitation was PPS might not be a representative of the real budget of each SD; PPS did not include total revenue, 
Table 4 Summary of injury reports to New Jersey Safe Schools Program state-law based surveillance system, 12/1998-06/2015

\begin{tabular}{lll}
\hline Characteristic & Total $(n)$ & Total (\%) \\
\hline Total Injury reports & a & \\
Gender & 2066 & \\
$\quad$ Male & & 72.2 \\
Female & 1475 & 27.8
\end{tabular}

Status

Student

Staff

Treatment

Hospital

Doctor

Injured Body Part

$\begin{array}{ll}\text { Finger } & 793 \\ \text { Hand } & 218 \\ \text { Multiple } & 199 \\ \text { Eye } & 158 \\ \text { Head } & 87 \\ \text { Foot } & 75 \\ \text { Arm } & 73 \\ \text { Face } & 60 \\ \text { Back } & 53 \\ \text { Ankle } & 51 \\ \text { Knee } & 42 \\ \text { Other } & 300\end{array}$

Injury Type

Cut/Laceration $\quad 815$

Burn

Multiple

Sprain

Bruise/Bump

Fracture

Puncture

Abrasion

Other

Injury Cause

Struck By

Struck Against

Extreme Temperature

Caught In/Under/Between

Fall (Same Level)

Multiple

Rubbed/Abraded

Other

Severity
37.6

10.3

9.4

7.5

4.1

3.6

3.5

2.8

2.5

2.4

2.0

14.2

300
Table 4 Summary of injury reports to New Jersey Safe Schools Program state-law based surveillance system, 12/1998-06/2015 (Continued)

\begin{tabular}{lll}
\hline Characteristic & Total $(\mathrm{n})$ & Total $(\%)$ \\
\hline Non-disabling & 1327 & 68.6 \\
Temporarily disabling & 606 & 31.3 \\
Permanent Disability & 1 & 0.1 \\
Personal Protective Equipment (PPE) & & \\
Yes & 303 & 49.3 \\
No & 311 & 50.7 \\
\hline
\end{tabular}

${ }^{a}$ Variables not adding up to total $(N=2066)$ indicated missing data points in injury report;

"Staff" not included in analysis

${ }^{b} P P E$ was not included in the older version of paper report from 1998 to 2003; yes and no indicate PPE used and no type of PPE used at the time of incidents, respectively

which includes other sources (non-state, private organization, community funding). Other limitations of this study were similar to our prior analyses with DFG scores as an SES indicator. [5] There were no denominator data. This study's data were reported incidents within CTE programs; there were no data of uninjured students/staff enrolled in CTE program between the school years 1998-2015. Another limitation related to the generalizability of results to the general secondary school/student population. Students enrolled in NJ CTE programs might not represent the overall student

Table 5 Injury reports to the New Jersey Safe Schools Program state-law based surveillance, 12/1998-06/2015, by per pupil spending (PPS) status

\begin{tabular}{|c|c|c|c|c|}
\hline \multirow[t]{2}{*}{ Characteristics } & \multicolumn{2}{|c|}{ Higher PPS ${ }^{a}$} & \multicolumn{2}{|c|}{ Lower PPS ${ }^{b}$} \\
\hline & Number & Percentage & Number & Percentage \\
\hline \multicolumn{5}{|l|}{ Gender } \\
\hline Male & 812 & 72.1 & 632 & 69.3 \\
\hline Female & 314 & 27.9 & 280 & 30.7 \\
\hline \multicolumn{5}{|l|}{ Treatment $(p=0.03)$} \\
\hline Hospital & 399 & 58.0 & 407 & 52.3 \\
\hline Doctor & 289 & 42.0 & 371 & 47.7 \\
\hline \multicolumn{5}{|l|}{ Severity $^{c}(p=0.0002)$} \\
\hline Non-disabling & 775 & 72.2 & 547 & 64.2 \\
\hline Temporary Disabling & 299 & 27.8 & 305 & 35.8 \\
\hline \multicolumn{5}{|c|}{ Personal Protective Equipment (PPE) Use ${ }^{d}(p=0.86)$} \\
\hline Yes & 101 & 50.0 & 202 & 48.9 \\
\hline No & 101 & 50.0 & 211 & 51.1 \\
\hline
\end{tabular}

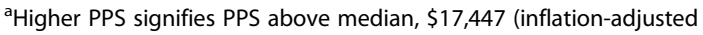
2010 U.S. dollars)

bLower PPS signifies PPS below median, \$17,447 (inflation-adjusted 2010 U.S. dollars)

'There was one permanent disability reported within the higher PPS group; no deaths reported

dYes and No indicated PPE used and no type of PPE used at the time of incidents, respectively 


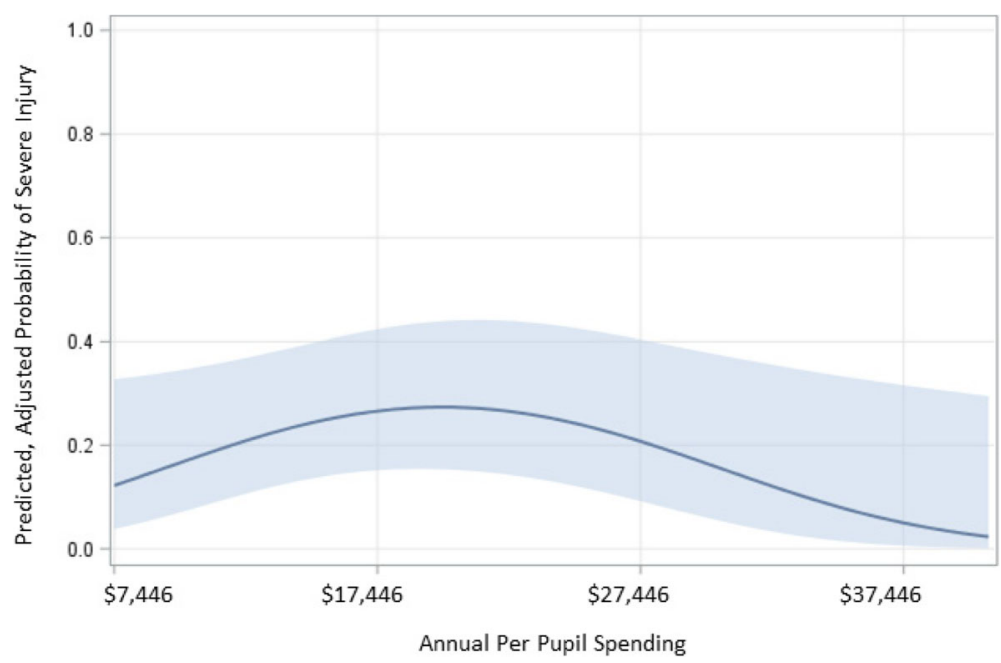

Fig. 1 Predicted, adjusted probability of experiencing a temporarily disabling injury by level of school district-level per pupil spending a,b a Adjusted for DFG score, location of treatment, and year of injury. ${ }^{b}$ Annual per pupil spending is inflation adjusted to 2010 U.S. dollars

population, especially general education students throughout NJ. Also, these students may not generalize to CTE students in other U.S. states, as CTE programs differ among each state. Furthermore, some PPS values were for a specific school within a SD, while some were based on the PPS of the overall SD, which might be only an estimation of the exact amount of PPS among each school reporting injuries. Finally, besides the well-known potential for information bias due to underreporting of data, one other issue related to certain missing or incomplete data fields. However, as of October 2013, reports have been only submitted online to NJSS via Psychdata. Thus, the problem about leaving certain spaces blank as sometimes occurred with the past paper-based injury surveillance system was eliminated. Other analyses compared completeness of reporting factors between the former paper-based and current online reporting system and are reported elsewhere. [24]

This study also had strengths. Data represented injury surveillance over 15 years for the State of NJ. Results inform the literature by specifically examining injuries relating to secondary school students enrolled in CTE programs by PPS as one major SES indicator, and are supported by a previous study [5] but now with 1.5 years more data.

\section{Conclusions}

The NJ Safe Schools Program/NJ Department of Education state law-based online surveillance system for youth/young workers in approved secondary school career-technical-vocational education programs allows examination of potential disparities regarding reportable work-related injuries by per pupil spending or PPS, an indicator of socioeconomic status, as well as by sex or gender, severity, safety training provided and work experience at time of injury. Future research should further explore these associations, and incorporate other attributes of the school environment as well as the presence (or not) of school policies on safety, health, and operations and maintenance of school facilities including classrooms. Moreover, development of enhanced injury prevention trainings and interventions could decrease numbers of reported injuries and thus help both decrease medical expenditures and increase student academic performance.

\section{Abbreviations}

CS: Charter schools; CTE: Career-technical-vocational education; DFG: District factor group score; ED: Emergency department; IRB: Institutional Review Board; NIOSH: National Institute of Occupational Safety and Health of the U.S. Centers for Disease Control and Prevention; NJ SS: New Jersey Safe Schools Program; NJ: State of New Jersey; NJDOE: New Jersey Department of Education; PPE: Personal protective equipment; PPS: Per pupil spending; SD: School district; SES: Socioeconomic status

\section{Acknowledgements}

We also thank other fellow NJ OSHA Alliance for Young Worker Safety and Health members for their support to promote the health and safety of minors. We also graciously acknowledge efforts of other NJ SS staff who contributed in past years.

\section{Funding}

We thank the New Jersey (NJ) Department of Education (NJDOE), Office of Career Readiness (formerly the Office of Career and Technical Education) for funding the NJ Safe Schools Program (NJ SS, per "Occupational Education and Safety and Health Training and Standards Updating" grant to the Rutgers School of Public Health) plus their staff for knowledge and expertise.

\section{Availability of data and materials}

This study's data are secured on computers per IRB approved stewardship of NJ SS and/or are also publicly available from New Jersey Department of Education. Datasets used and analyzed during the current study are available from the corresponding author on reasonable request. 


\section{Author's contributions}

DGS led the writing and editing of this manuscript, and reviewed preliminary and final data analyses. SN and AAA led database assimilation, management and analyses and assisted with literature review and editing of this manuscript. JJP led final advanced statistical analyses and both wrote specific paragraphs and assisted with overall editing of this manuscript. Each of the four authors have read and approved the final manuscript.

\section{Ethics approval and consent to participate}

All procedures performed in studies involving human participants were in accordance with the ethical standards of the institutional and/or national research committee and with the 1964 Helsinki declaration and its later amendments or comparable ethical standards.

Rutgers University-New Brunswick Institutional Review Board (IRB) has approved NJ Safe Schools Program (NJSS) incident surveillance and training-related evaluation activities as exempt research since they are based on various State of New Jersey (NJ) laws (IRB \#021997 W0383). Data used in this study are either: openly available via NJ Department of Education (NJDOE), i.e., per-pupil spending data through local and county (districts or schools) and state (NJDOE) websites; or, injury data in deidentified form can be available via NJSS upon a formal written request approved by NJDOE. Our study obtained the necessary administrative permissions by the NJDOE to analyze these data, which are reported by State of NJ law directly to NJSS, as a grantee of NJDOE, or directly to NJDOE by the school districts and their secondary schools.

\section{Consent for publication}

Not applicable.

\section{Competing interests}

The authors declare that they have no competing interests.

\section{Publisher's Note}

Springer Nature remains neutral with regard to jurisdictional claims in published maps and institutional affiliations.

\section{Author details}

${ }^{1}$ Environmental and Occupational Health And New Jersey Safe Schools Program (NJ SS) Rutgers School of Public Health, 683 Hoes Lane West, 3rd Floor SPH Building, Piscataway, NJ 08854-8020, USA. ${ }^{2}$ University of Illinois-Chicago, Chicago, USA. ${ }^{3}$ Department of Epidemiology, Rutgers School of Public Health, Piscataway, USA. ${ }^{4}$ School of Public Health, The University of North Carolina, Chapel Hill, USA.

Received: 14 December 2017 Accepted: 5 October 2018

Published online: 20 October 2018

\section{References}

1. National Institute of Occupational Safety and Health, Young worker safety and health. 2015. http://www.cdc.gov/niosh/topics/youth/. Accessed 8 Aug 2016.

2. National Institute of Occupational Safety and Health, Data Overview of Young Worker Deaths and Injuries, United States 2011. http://www.cdc.gov/ niosh/topics/youth/chtpkgfig5.html. Accessed 8 Aug 2016.

3. Young M, Rischitelli DG. Occupational risks and risk perception among Hispanic adolescents. McGill J Med. 2006;9(1):49-53.

4. Laberge L, Ledoux É, Auclair J, et al. Risk factors for work-related fatigue in students with school-year employment. J Adolesc Health. 2011;48(3):289-94.

5. Apostolico AA, Shendell DG. Injury surveillance and associations with socioeconomic status indicators among youth/young workers in New Jersey secondary schools. Environ Health. 2016;15(1):1-9.

6. Census Bereau US. Per pupil spending varies heavily across the United States: Census publication Financial; 2015. https://www.census.gov/ newsroom/press-releases/2015/cb15-98.html. Accessed 8 Aug 2016.

7. Johnson RC. The health returns of education policies from preschool to high school and beyond. Am Econ Rev. 2010;100(2):188-94.

8. Sage SK, Gerberich SG, Ryan AD, et al. School resources, resource allocation, and risk of physical assault against Minnesota educators. Accid Anal Prev. 2010;42(1):1-9.

9. Brener ND, Jones SE, Kann L, McManus T. Variation in school health policies and programs by demographic characteristics of US schools. J Sch Health. 2003;73(4):143-9.
10. Cubbin C, LeClere FB, Smith GS. Socioeconomic status and the occurrence of fatal and nonfatal injury in the United States. Am J Public Health. 2000; 90(1):70-7.

11. Runyan CW, Zakocs RC. Epidemiology and prevention of injuries among adolescent Workers in the United States. Annu Rev Publ Health. 2000;21(1):247-69.

12. Rauscher KJ, Myers DJ. Socioeconomic disparities in the prevalence of workrelated injuries among adolescents in the United States. J Adolesc Health. 2008;42(1):50-7.

13. Schulte PA, Stephenson CM, Okun AH, et al. Integrating occupational safety and health information into vocational and technical education and other workforce preparation programs. Am J Public Health. 2005;95(3):404-11.

14. Zierold KM, Appana S, Anderson HA. School-sponsored work programs: a first look at differences in work and injury outcomes of teens enrolled in school-to-work programs compared to other-working teens. Occup Environ Med. 2011;68(11):818-25.

15. Shendell DG, Hemminger LE, Campbell JK, Schlegel B. Supervising structured learning experiences for students in New Jersey: training teachers in school-based occupational health and safety practice. Public Health Rep. 2009;124(Suppl 1):74-83.

16. Shendell DG, Jhaveri M, Nowakowski AC, et al. Incident surveillance in New Jersey career and technical education programs, 1999 to 2008: attributes, severity, and reported use of personal protective equipment. AAOHN J. 2010;58(9):367-80.

17. Shendell DG, Mizan SS, Marshall EG, et al. Cut-laceration injuries and related career groups in New Jersey career, vocational, and technical education courses and programs. Workplace Health Saf. 2012;60(9):401-9 quiz 410.

18. New Jersey Department of Education, Taxpayers' guide to education spending. 2016. http://www.nj.gov/education/guide/2015/intro.pdf. Accessed 8 Aug 2016

19. U.S. Department of Labor, Bureau of Labor Statistics. Consumer price index. 2017. https://www.bls.gov/cpi/. Accessed 14 Oct 2018.

20. Goldstein H. Multilevel Statistical Models. 3. London: Arnold; 2003. p. 253.

21. Malek M, Chang BH, Gallagher SS, et al. The cost of medical care for injuries to children. Ann Emerg Med. 1991;20(9):997-1005.

22. Michaels D. Adding inequality to injury: the costs of failing to protect workers on the job. U.S. Department of Labor-Occupational Safety \& Health Administration. 2015. https://www.osha.gov/news/speeches/06182015. Accessed 14 Oct 2018.

23. Condron DJ, Roscigno VJ. Disparities within: unequal spending and achievement in an Urban School district. Sociol Educ. 2003;76(1):18-36.

24. Shendell DG, Milich LJ, Apostolico AA, Cordon TP, Patti AA. Injury surveillance among youth/young workers: Initial efficacy of a law-based online system versus original paper-based format.. Oral presentation at NIOSH National Occupational Injury Research Symposium, Morgantown, WW, October 2015 and submitted as approved final report to the NJ Department of Education for 2016-2017 contract.

Ready to submit your research? Choose BMC and benefit from:

- fast, convenient online submission

- thorough peer review by experienced researchers in your field

- rapid publication on acceptance

- support for research data, including large and complex data types

- gold Open Access which fosters wider collaboration and increased citations

- maximum visibility for your research: over $100 \mathrm{M}$ website views per year

At BMC, research is always in progress.

Learn more biomedcentral.com/submissions 